Research Article

\title{
Biological Effects of Plasma-Based Graphene Oxide Deposition on Titanium
}

\author{
Keonho Rho, ${ }^{1}$ Chan Park ${ }^{D},{ }^{2}$ Khurshed Alam, ${ }^{1}$ Dongyun Kim, ${ }^{1}$ Min-Kyung Ji, ${ }^{2}$ \\ Hyun-Pil Lim $\mathbb{D}^{2}{ }^{2}$ and Hoonsung Cho $\mathbb{D}^{1}$ \\ ${ }^{1}$ School of Materials Science and Engineering, Chonnam National University, Gwangju, Republic of Korea \\ ${ }^{2}$ Department of Prosthodontics, School of Dentistry, Chonnam National University, Gwangju, Republic of Korea \\ Correspondence should be addressed to Hyun-Pil Lim; mcnihil@jnu.ac.kr and Hoonsung Cho; cho.hoonsung@jnu.ac.kr
}

Received 8 March 2019; Revised 30 July 2019; Accepted 22 August 2019; Published 3 November 2019

Academic Editor: Ping Xiao

Copyright (C) 2019 Keonho Rho et al. This is an open access article distributed under the Creative Commons Attribution License, which permits unrestricted use, distribution, and reproduction in any medium, provided the original work is properly cited.

\begin{abstract}
This study was performed to investigate the effects of argon plasma treatment under atmospheric pressure at room temperature on the cytotoxicity and antimicrobial effects of the graphene oxide layer on titanium. Plasma treatment of the graphene oxide coating on a nonthermal atmospheric-pressure plasma device was performed. Raman spectrum analysis confirmed that graphene oxide was successfully coated on the surface and AFM analysis confirmed that this coating affected the surface roughness. X-ray photoelectron spectroscopy (XPS), Alizarin Red S staining for cell differentiation, and Raman and atomic force microscopy (AFM) analyses were performed for the deposited surface. The MTT (3-(4,5-dimethylthiazol-2-yl)-2,5-diphenyltetrazolium bromide) assay was performed to confirm the biocompatibility of the plasma-treated and bare titanium specimens. The biofilm formation test using Streptococcus mutans (S. mutans) was performed to examine potential antimicrobial effects. XPS analysis showed that with increasing plasma coating time, the carbon content of the surface decreased while that of oxygen increased. Alizarin Red $S$ staining showed that the cell differentiation was promoted by the deposition of the graphene oxide. The graphene oxide on Ti significantly affected an osteoblast cell differentiation for bone growth, and no significant differences in antimicrobial effects were observed.
\end{abstract}

\section{Introduction}

In dentistry, titanium is widely used especially in dental implants [1]. The biocompatible nature of titanium shows a very high success rate when used as a dental implant in the oral cavity [2]. However, many scientists are working on various attempts to produce effects beyond the nature of titanium [3]. One such attempt is the improvement of titanium surface properties to increase the bonding strength to the bone.

Changes in the titanium surface have been tried variously [4]. Calcium, hydroxyapatite, etc. have been used to induce chemical adhesion $[5,6]$. So far, many attempts have been made to develop dental implants, but the initial fixation force there is a need for a more innovative material to dramatically increase. Here, we are noticing the effect of graphene, which has been widely used in existing biomaterial parts. Graphene is one of the carbon-based materials [7, 8]. It consists of a single layer of sp2-hybridized carbon atoms and is known as the basic component of fullerenes and carbon nanotubes [9-11]. In addition to the physical properties, they have been shown to be highly biocompatible [12-14].

There are many ways to apply graphene to titanium surfaces [10-22]. Among them is atmospheric-pressure plasma at room temperature [23, 24]. Plasma is the state of the fourth substance and is different from solid, liquid, or gas [25]. Plasma is a state of matter separated by negatively charged electrons and positively charged ions [26]. Plasma is often generated when a gas is charged with high energy, but various attempts have been made to utilize it by generating plasma at 


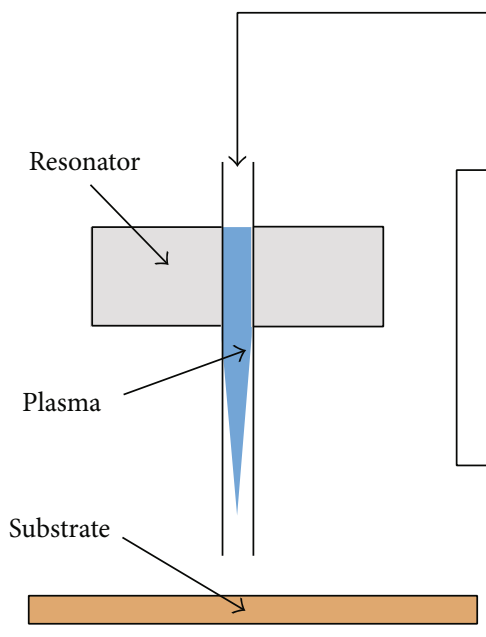

(a)

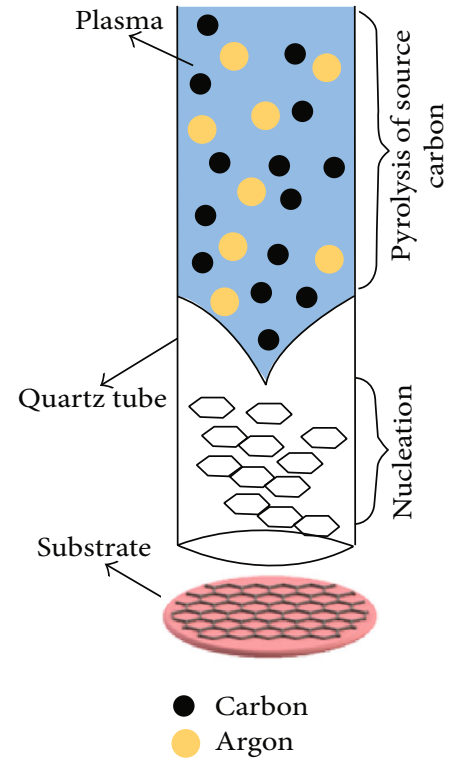

(b)

FIgURE 1: (a) Schematic diagram of the atmospheric plasma instrument. (b) The deposition process of the graphene oxide: decomposition of methane in the high-densed plasma and carbon-carbon bonding through the tube.

room temperature and atmospheric pressure for applications in the human body $[27,28]$.

A method in which various gases passing through plasma decompose carbon-containing molecules into atoms to form graphene $[29,30]$. The quality of graphene depends on the velocity of gas and the power of plasma [31]. However, there is a lack of research on plasma-based graphene generation. Therefore, in this study, we produced graphene using nonthermal atmospheric-pressure plasma, which was then coated on titanium and experimented variously. In the experiment, we attempted to confirm the feasibility of titanium coating using plasma and analyze the various cytotoxic and antimicrobial effects. The null hypothesis of this experiment is that plasma-based graphene does not affect the cytotoxic and antimicrobial effects of titanium.

\section{Materials and Methods}

2.1. Preparation of the Specimen and Plasma Treatment. The study materials are commercially available pure grade 2 titanium (thickness: $3 \mathrm{~mm}$, diameter: $15 \mathrm{~mm}$ ). Each specimen was sequentially polished with \#400 to \#2000 grit silicon carbide sandpaper, $1 \mu \mathrm{m}$ alumina powder, and a polishing cloth. Deposition of the graphene oxide on the titanium substrate was performed by a nonthermal atmospheric plasma generator PGS-300 (Expantech Co., Suwon, Korea). Figure 1(a) shows the atmospheric plasma system for the graphene oxide on Ti substrate. Argon gas was used as a plasma carrier and mixed with methane gas for the carbon source. To generate plasma, 41/min of argon gas was carried through the resonator and the plasma was generated by the high radio frequency $(900 \mathrm{MHz})$ resonance plasma generator $(300 \mathrm{~W})$. Once the plasma stabilized, 60 SCCM of the mixture gas (10\% methane) was introduced into a quartz tube, and the deposition of the graphene oxide initiated. Figure 1(b) shows the depo- sition process of the plasma-based graphene oxide. The high-densed plasma induced the decomposition of methane into hydrogen and carbon. During the decomposed carbon flows down through the tube, the carbon-carbon bond is formed and the two-dimensional layers of the graphene oxide are deposited on a Ti substrate. The plasma was processed for a total of $60 \mathrm{~s}$.

2.2. Surface Analysis. The surface characteristics of the deposited plasma-based graphene film were analyzed by X-ray photoelectron spectroscopy (XPS), Raman spectroscopy, and atomic force microscopy (AFM). XPS (VG Multilab 2000, ThermoVG Scientific, Southend-on-Sea, Essex, UK) confirmed the surface argon atomic composition appearance and the other compositions. Raman spectroscopy (NRS5100, JASCO, Tokyo, Japan) was performed with a $532 \mathrm{~nm}$ laser to confirm the presence of graphene oxide on the titanium surface. AFM (Nanoscope-III, Digital Instruments, Santa Barbara, CA, USA) was used to confirm the plasma effect on the average surface roughness $\left(R_{\mathrm{a}}\right)$.

2.3. In Vitro Testing. Cytotoxicity and antibacterial activity of the graphene oxide-deposited titanium were evaluated by MTT assay and Alizarin Red S stain and compared with pure titanium $(n=8)$. The L-929 mouse fibroblasts cells (NCTC clone 929, ATCC $^{\circledR}$ CCL- ${ }^{\mathrm{TM}}$ ) were used for cytotoxicity test. Eight specimens from each group were placed in a 24 -well plate. L-929 cells were seeded at a density of $1 \times 10^{5}$ cells/ well and incubated for 3 days. Cytotoxicity was evaluated by the MTT assay(3-(4,5-dimethylthiazon-2-yl)-2,5-diphenyl tetrazolium bromide, M6494, Invitrogen, USA). MC3T3-E1 mouse osteoblast cells (MC3T3-E1 subclone 4, ATCC ${ }^{\circledR}$ CRL-2593 ${ }^{\mathrm{TM}}$ ) were used for the cell differentiation test. Eight specimens from each group were plated in a 24-well plate and cells were incubated at a density of $1 \times 10^{5}$ cells/well in each 


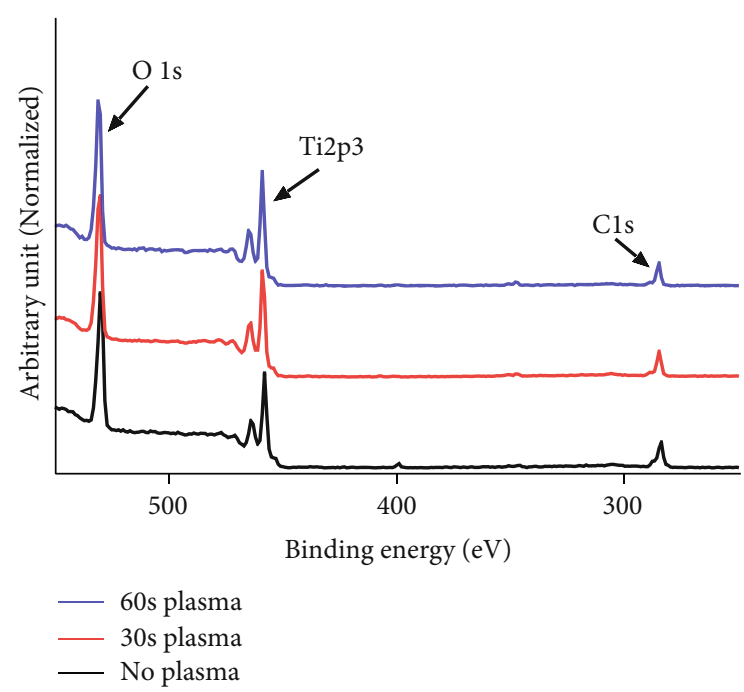

FIGURE 2: XPS wide spectra survey of the initial Ti surface and that observed after $60 \mathrm{~s}$ of plasma treatment. To further examine plasma treatment effects, XPS analysis was also performed after plasma treatment for $30 \mathrm{~s}$.

well. Osteoblast differentiation evaluated by Alizarin Red S stain (A5533, Sigma-Aldrich, St. Louis, MO, USA) after designated time periods of incubation. The antibacterial activity test was conducted using S. mutans (Korean Collection for Oral Microbiology, KCOM, Gwangju, Korea, KCOM 1504). S. mutans was maintained in brain heart infusion (BHI) broth (Becton, Dickinson and Co. Sparks, MD, USA). Eight specimens from each group were placed in a 24 -well plate and incubated with $1 \mathrm{ml}$ of a $1.5 \times 10^{7}$ cells $/ \mathrm{ml}$ bacterial suspension for 24 hours at $37^{\circ} \mathrm{C}$. After the incubation, one hundred microliters of the bacterial suspensions was transferred to $900 \mu \mathrm{l}$ of phosphate-buffered saline (PBS) and diluted up to $10^{-6}$. A $100 \mu \mathrm{l}$ aliquot of the diluted solution was plated on BHI agar (Agar, Becton, Dickinson and Company, Sparks, $\mathrm{MD}$, USA) plates, applied evenly with a spreader, and cultured at $37^{\circ} \mathrm{C}$ for 2 days. At the end of the incubation period, the number of colonies (colony-forming units) was counted on BHI agar plates.

2.4. Statistical Analyses. All statistical analyses were analyzed by statistics software (SPSS version 20.0, IBM Korea Inc., Seoul, Korea). The cytotoxicity and antibacterial effects were evaluated by one-way analysis of variance, and post hoc comparisons were processed by Tukey's test. A $p$ value of $<0.05$ was considered significant.

\section{Results and Discussion}

\subsection{Surface Analysis}

3.1.1. XPS. Comparison of XPS spectra survey scan in Figure 2 reveals the relative ratio of carbon decreased while that of oxygen increased with increasing plasma treatment time. The results show that hydrocarbon layers were removed by the plasma treatment, and the titanium oxide layer was revealed. Table 1 summarizes the surface atomic
TABLE 1: The surface atomic composition by XPS.

\begin{tabular}{lccc}
\hline Elements & No plasma & $\begin{array}{c}\text { Atomic } \% \\
\text { 30 s plasma }\end{array}$ & 60 s plasma \\
\hline C1s & 26.86 & 23.57 & 20.14 \\
O1s & 60.77 & 62.79 & 63.99 \\
Ti2p3 & 12.37 & 13.64 & 15.87 \\
\hline
\end{tabular}

composition by the plasma treatment. The carbon content decreased from $26.86 \%$ to $20.14 \%$, whereas the oxygen ratio increased from $60.77 \%$ to $63.90 \%$ after plasma treatment for $60 \mathrm{~s}$. The titanium composition increased from $12.37 \%$ to $15.87 \%$ with increasing argon plasma treatment time.

3.1.2. Alizarin Red S Staining and MTT Assay. Figure 3 shows the growth of fibroblast cells after three days of incubation on the plasma-treated titanium surface with a none-treated $\mathrm{Ti}$ surface and on a well plate for comparison. The surface of the pure titanium specimen was less biocompatible than that of the cell culture plate and plasma-treated titanium. The argon plasma-treated titanium surface was more biocompatible than that of pure titanium. This figure does not include the results of the cell counting method, but the images clearly indicate the cell affinities of the various surfaces. The cell culture plate was coated with positively charged glucose, which was optimized for uniform distribution of cells bearing negative charge. The cells were well distributed on the cell culture plate and plasma-treated titanium surface. This result corresponds with the data of MTT assay (Figure 4) indicating that the plasma treatment enhanced the cell affinity on the surface by increasing hydrophilicity.

3.1.3. Raman Spectroscopy. The Raman spectra were used to determine the characteristics of surface graphene oxide film and were effective for analyzing the plasma-based graphene film. Raman spectroscopy can distinguish between the presence of graphene or graphene oxide, evaluate crystallinity, and determine the defect levels of the surface carbon film.

The Raman spectra of graphene typically show three distinct peaks: D, G, and 2D (also called $\mathrm{G}^{\prime}$ ) peaks. Typical Raman spectra of graphene oxides are characterized by $G$ and D peaks at 1605 and $1353 \mathrm{~cm}^{-1}$, respectively, while graphene typically exhibits $G$ and $D$ peaks at 1580 and $1350 \mathrm{~cm}^{-1}$, respectively $[32,33]$.

Figure 5 shows two lines taken from the different treatment times for the deposition of graphene oxides. The graph of 5 min deposition time shows the $G$ and $D$ peaks at 1608 and $1351 \mathrm{~cm}^{-1}$, and the graph of $10 \mathrm{~min}$ deposition time also shows the peaks at 1608 and $1352 \mathrm{~cm}^{-1}$ with increase of the intensity, respectively. Slight shifts from the ideal positions can be generated by defects such as vacancies, grain boundaries, and amorphous carbon species [34-36]. From these results, we can conclude that the surface film deposited on the titanium surface was graphene oxide.

3.1.4. AFM Analysis. Figure 6 shows the 3-dimentional atomic force microscope (AFM) images over a $5 \mu \mathrm{m} \times 5 \mu \mathrm{m}$ scanned area, which confirmed the surface carbon deposition. 


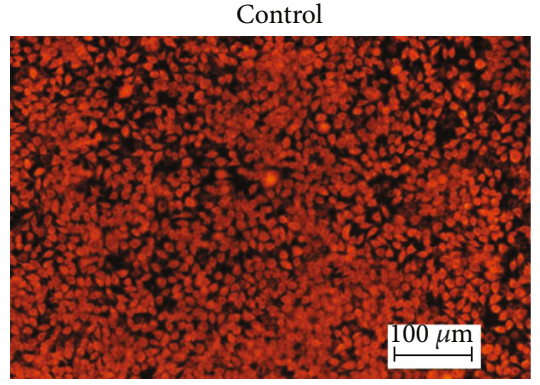

(a)

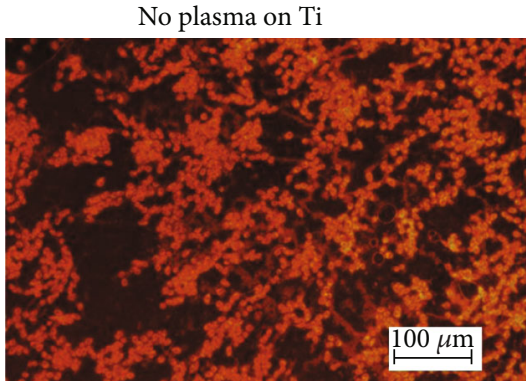

(b)

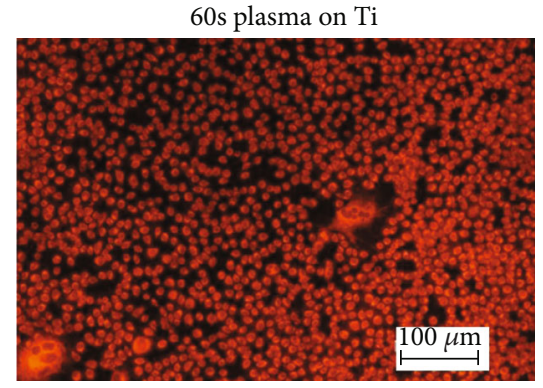

(c)

FIGURE 3: NCTC L-929 cell neutral red staining of the plasma-treated titanium. All scale bars indicate $100 \mu \mathrm{m}$. (a) Cell culture plate, (b) pure titanium, and (c) titanium with plasma treatment.

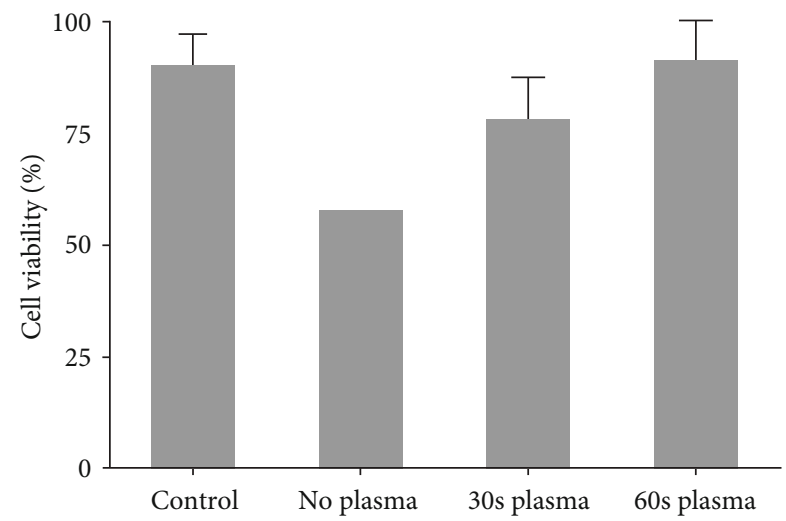

FIgURE 4: MTT assay showing the biocompatibility of the various surface conditions with the result on a cell culture plate for control. After the plasma treatment with the indicated time, the L-929 mouse fibroblasts cells incubated on the surface for 3 days and MTT assay was performed. The argon plasma treatment enhanced the cell viability on the Ti surface. The biocompatibility of titanium treated for 60 -second plasma treatment showed same as that of the cell culture plate.

In Figure 6, the as-polished titanium showed a smooth surface (Figure 6(a)) with $R_{\mathrm{a}}$ of $0.589 \mathrm{~nm}$ and the plasmatreated surface (Figure 6(b)) with $R_{\mathrm{a}}$ of 0.857 compared with the carbon film-deposited specimen, which exhibited an $R_{\mathrm{a}}$ of $9.258 \mathrm{~nm}$ (Figure 6(c)), which is 15.7 times higher than that of the polished titanium surface. The surface topographies also support the surface deposition of materials.

\subsubsection{Alizarin Red S Staining for the Osteoblast Cell} Differentiation. Alizarin Red S staining shows amount of metal ions (calcium ions are the target in this experiment) made by osteoblast cell differentiation on the specimen surface. Figure 7(a) shows the activity of promoted MC3T3-E1 osteoblast cells on the graphene oxide-deposited $\mathrm{Ti}$ compared with the cell culture plate indicating the enhancement of the growth, attachment, and differentiation of the osteoblast cell on the graphene oxide-deposited Ti. Both results showed that the surface-treated titanium specimen is superior in cell activity to the cell culture plate. The carbon-deposited titanium can be a better substrate for MC3T3-E1 osteoblast cell to grow and differentiate for making bone flakes.

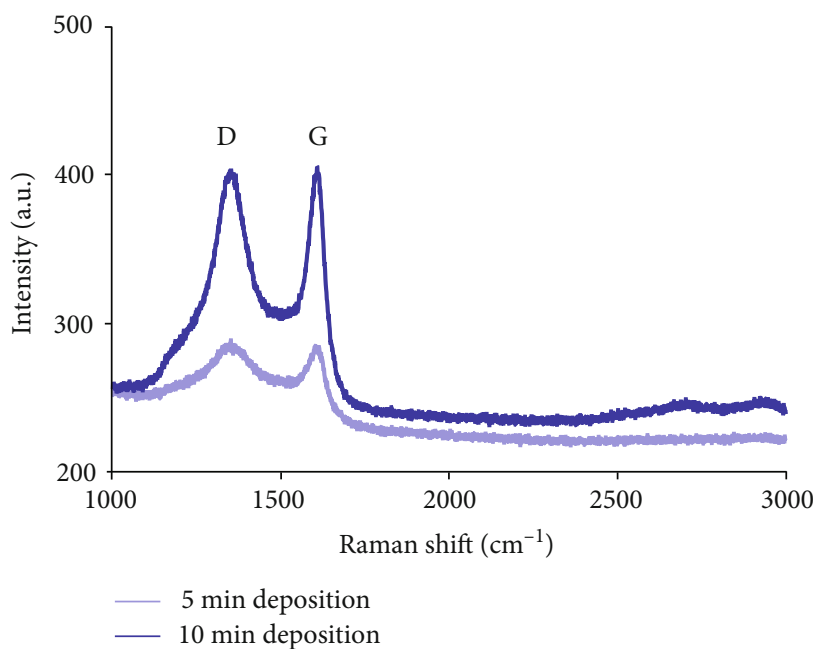

FIgURE 5: Raman spectra for the analysis of the generated graphene oxide surface indicating that the deposited carbon film was graphene oxide layers.

3.1.6. Antibacterial Effects. Comparison of the observed CFUs shows the antibacterial properties of the graphene oxide plasma-treated titanium surface [37]. Because the starting bacterial concentration was identical, only the effects of the specimen influenced bacterial proliferation. Titanium coated with the graphene oxide film was expected to exhibit beneficial antibacterial properties and decreased bacterial growth. In Figure 7(b), the plasma-treated titanium specimen showed a $3.45 \%$ decrease in the amount of proliferated bacteria compared with the control (cell culture plate). Although the graphene oxide-deposited specimen showed antibacterial activity, the intensity of the effect was negligible, and this difference was not statistically significant. Compared with the as-polished titanium specimen, there was no significant change of antibacterial effect by the graphene oxide. Even though some antimicrobial effect was observed, it could not be determined whether this effect originated from the plasma or graphene.

The Raman spectra confirmed that our plasma system effectively deposited graphene oxide layers on the titanium surface [38]. The method developed herein is effective for examining the effect of plasma and the effects of the deposition of the graphene oxide. The changes in carbon and 


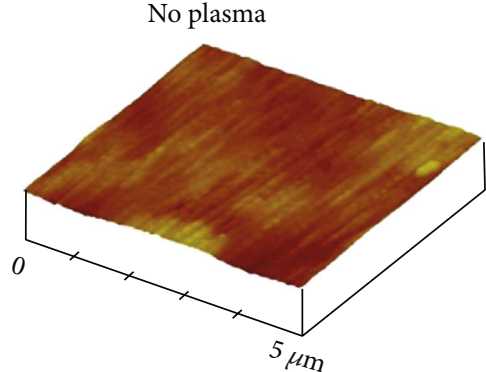

$R_{\mathrm{a}}=0.589 \mathrm{~nm}$

(a)

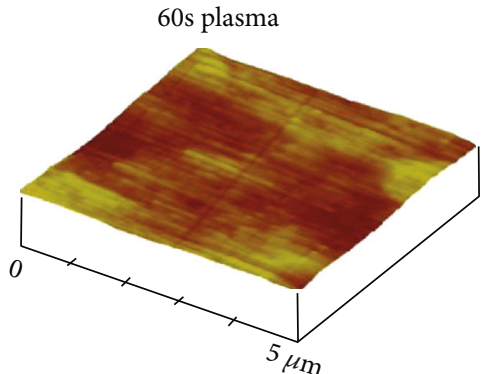

$R_{\mathrm{a}}=0.857 \mathrm{~nm}$

(b)

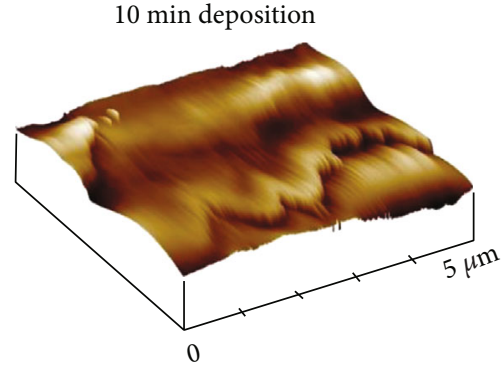

$R_{\mathrm{a}}=9.258 \mathrm{~nm}$

(c)

FIGURE 6: AFM results of the 3D surface morphology and roughness of the (a) polished titanium and (b) plasma-treated titanium samples.

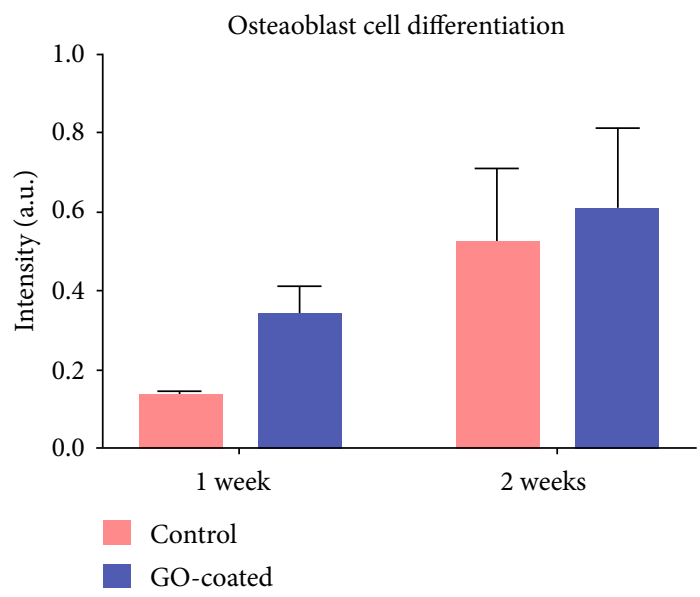

(a)

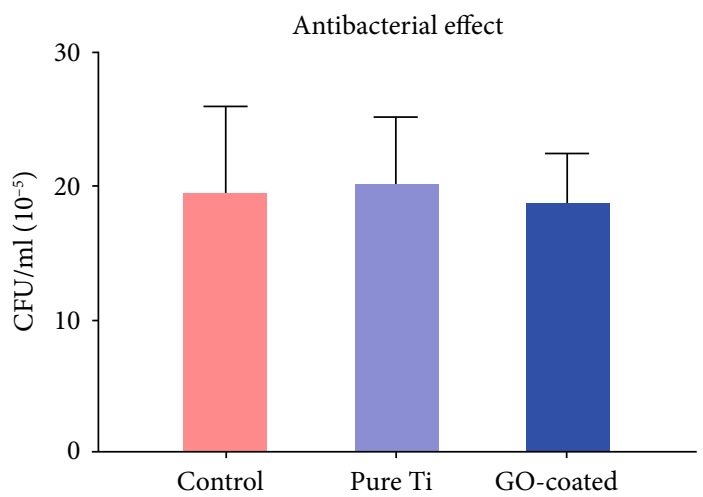

(b)

Figure 7: In vitro effect of the graphene oxide layers on Ti. (a) Alizarin Red S staining results indicating the enhancement of the growth, attachment, and differentiation of the osteoblast cell. (b) The antibacterial effect of the plasma-treated titanium specimen with graphene oxide coating. No significant difference in antibacterial effect was observed when compared with the control (a cell culture plate).

oxygen content as determined by XPS analysis were similar to those observed for conventional plasma treatment [39].

It is surprising that the antimicrobial effects of the plasma treatment and the graphene oxide were muted. These effects have also been associated with increased surface roughness, but in general, an increase in surface roughness results in increased bacterial attachment to the surface [40]. In our experiments, the deposition of the plasma-based graphene oxide resulted in a significant increase in surface roughness (Figure 6). Therefore, it is likely that the antimicrobial effect could be enhanced if the surface roughness could be controlled. The development of a deposition method that does not increase surface roughness would likely improve antibacterial activity.

Previous publications reported an enhancement of the osteoblast cell differentiation and antimicrobial effects of graphene oxide and the plasma treatment [17, 41-43]. In this study, no statistically significant differences of the antimicrobial effect between the experimental and control groups were observed; however, a solid increase in osteoblast cell differentiation was measured. This can be attributed to the good biocompatibility of titanium.

\section{Conclusions}

From the limited results of this study, we can conclude the following:

(1) The graphene oxide prepared with nonthermal atmospheric-pressure plasma can be effectively applied to titanium surfaces

(2) The argon plasma treatment enhanced biocompatibility of titanium equivalent to that of the cell culture plate

(3) The deposition of graphene oxide using nonthermal atmospheric-pressure plasma would promote bone growth in the vicinity of the implant by enhancing osteoblast cell differentiation

\section{Data Availability}

The data obtained for this study are presented in the tables and figures herein. In addition, you may contact the corresponding authors to request for the original datasets at any time. 


\section{Conflicts of Interest}

The authors declare no conflict of interest.

\section{Authors' Contributions}

Keonho Rho and Chan Park contributed equally to this work.

\section{Acknowledgments}

This research was supported by the National Research Foundation of Korea (NRF) grant funded by the Korean government (MSIP; No. 2017R1A2B4007769) and the Chonnam National University (2014-0615 and 2015-1830).

\section{References}

[1] T. Albrektsson and L. Sennerby, "State of the art in oral implants," Journal of Clinical Periodontology, vol. 18, no. 6, pp. 474-481, 1991.

[2] E. P. Lautenschlager and P. Monaghan, "Titanium and titanium alloys as dental materials," International Dental Journal, vol. 43, no. 3, pp. 245-253, 1993.

[3] G. Mendonça, D. B. S. Mendonça, F. J. L. Aragão, and L. F. Cooper, "Advancing dental implant surface technology-from micron-to nanotopography," Biomaterials, vol. 29, no. 28, pp. 3822-3835, 2008.

[4] J. B. Brunski, "Biomechanics of oral implants: future research directions," Journal of Dental Education, vol. 52, pp. 775787, 1988.

[5] L. Le Guéhennec, A. Soueidan, P. Layrolle, and Y. Amouriq, "Surface treatments of titanium dental implants for rapid osseointegration," Dental Materials, vol. 23, no. 7, pp. 844854, 2007.

[6] S. D. Cook, J. F. Kay, K. A. Thomas, and M. Jarcho, "Interface mechanics and histology of titanium and hydroxylapatitecoated titanium for dental implant applications," International Journal of Oral \& Maxillofacial Implants, vol. 2, pp. 14-27, 1987.

[7] D. Cavallo, C. Fanizza, C. L. Ursini et al., "Multi-walled carbon nanotubes induce cytotoxicity and genotoxicity in human lung epithelial cells," Journal of Applied Toxicology, vol. 32, no. 6, pp. 454-464, 2012.

[8] A. Singh, G. Ehteshami, S. Massia, J. He, R. G. Storer, and G. Raupp, "Glial cell and fibroblast cytotoxicity study on plasma-deposited diamond-like carbon coatings," Biomaterials, vol. 24, no. 28, pp. 5083-5089, 2003.

[9] K. S. Novoselov, V. I. Fal'ko, L. Colombo, P. R. Gellert, M. G. Schwab, and K. Kim, "A roadmap for graphene," Nature, vol. 490, pp. 192-200, 2012.

[10] Y. Xie, H. Li, C. Ding, X. Zheng, and K. Li, "Effects of graphene plates' adoption on the microstructure, mechanical properties, and in vivo biocompatibility of calcium silicate coating," International Journal of Nanomedicine, vol. 10, pp. 3855-3863, 2015.

[11] M. Poot and H. S. van der Zant, "Nanomechanical properties of few-layer graphene membranes," Applied Physics Letters, vol. 92, 2008.

[12] J. Kim, Y.-R. Kim, Y. Kim et al., "Graphene-incorporated chitosan substrata for adhesion and differentiation of human mesenchymal stem cells," Journal of Materials Chemistry B, vol. 1, pp. 933-938, 2013.

[13] S. Y. Park, J. Park, S. H. Sim et al., "Enhanced differentiation of human neural stem cells into neurons on graphene," Advanced Materials, vol. 23, pp. 263-267, 2011.

[14] Y. C. Shin, J. H. Lee, L. Jin et al., "Stimulated myoblast differentiation on graphene oxide-impregnated PLGA-collagen hybrid fibre matrices," Journal of Nanobiotechnology, vol. 13, p. 1, 2015.

[15] B. S. Harrison and A. Atala, "Carbon nanotube applications for tissue engineering," Biomaterials, vol. 28, pp. 344-353, 2007.

[16] C. Kaya, I. Singh, and A. R. Boccaccini, "Multi-walled carbon nanotube-reinforced hydroxyapatite layers on Ti6Al4V medical implants by electrophoretic deposition (EPD)," Advanced Engineering Materials, vol. 10, pp. 131-138, 2008.

[17] W. Hu, C. Peng, W. Luo et al., "Graphene-based antibacterial paper," ACS Nano, vol. 4, pp. 4317-4323, 2010.

[18] Z. Liu, J. T. Robinson, X. Sun, and H. Dai, "PEGylated nanographene oxide for delivery of water-insoluble cancer drugs," Journal of the American Chemical Society, vol. 130, pp. 10876-10877, 2008.

[19] C. E. Misch, Contemporary Implant Dentistry-E-Book: Arabic Bilingual Edition, Elsevier Health Sciences, 2007.

[20] T. Driskell, "History of implants," Journal of the California Dental Association, vol. 15, pp. 16-25, 1987.

[21] T. Albrektsson, G. Zarb, P. Worthington, and A. Eriksson, "The long-term efficacy of currently used dental implants: a review and proposed criteria of success," The International Journal of Oral \& Maxillofacial Implants, vol. 1, pp. 11-25, 1986.

[22] S. Chuang, L. Wei, C. Douglass, and T. Dodson, "Risk factors for dental implant failure: a strategy for the analysis of clustered failure-time observations," Journal of Dental Research, vol. 81, pp. 572-577, 2002.

[23] F. Zhang, Z. Zhang, X. Zhu, E.-T. Kang, and K.-G. Neoh, "Silkfunctionalized titanium surfaces for enhancing osteoblast functions and reducing bacterial adhesion," Biomaterials, vol. 29, no. 36, pp. 4751-4759, 2008.

[24] L. Zhao, Y. Hu, D. Xu, and K. Cai, "Surface functionalization of titanium substrates with chitosan-lauric acid conjugate to enhance osteoblasts functions and inhibit bacteria adhesion," Colloids and Surfaces B: Biointerfaces, vol. 119, pp. 115-125, 2014.

[25] X. Li, J. Tian, T. Nguyen, and W. Shen, "Based microfluidic devices by plasma treatment," Analytical Chemistry, vol. 80, no. 23, pp. 9131-9134, 2008.

[26] I. H. Hutchinson, "Principles of plasma diagnostics," Plasma Physics and Controlled Fusion, vol. 44, no. 12, p. 2603, 2002.

[27] V. Arora, "Cold atmospheric plasma (CAP) in dentistry," Dentistry, vol. 04, no. 1, 2013.

[28] S. Cha and Y. Park, "Plasma in dentistry," Clinical Plasma Medicine, vol. 2, no. 1, pp. 4-10, 2014.

[29] T. N. Lambert, C. C. Luhrs, C. A. Chavez, S. Wakeland, M. T. Brumbach, and T. M. Alam, "Graphite oxide as a precursor for the synthesis of disordered graphenes using the aerosolthrough-plasma method," Carbon, vol. 48, no. 14, pp. 40814089, 2010.

[30] J. Phillips, C. C. Luhrs, and M. Richard, "Review: engineering particles using the aerosol-through-plasma method," IEEE 
Transactions on Plasma Science, vol. 37, no. 6, pp. 726-739, 2009.

[31] M. Yi and Z. Shen, "A review on mechanical exfoliation for the scalable production of graphene," Journal of Materials Chemistry $A$, vol. 3, no. 22, pp. 11700-11715, 2015.

[32] F. T. Johra, J.-W. Lee, and W.-G. Jung, "Facile and safe graphene preparation on solution based platform," Journal of Industrial and Engineering Chemistry, vol. 20, no. 5, pp. 2883-2887, 2014.

[33] S. Perumbilavil, P. Sankar, T. P. Rose, and R. Philip, "White light Z-scan measurements of ultrafast optical nonlinearity in reduced graphene oxide nanosheets in the $400-700 \mathrm{~nm}$ region," Applied Physics Letters, vol. 107, no. 5, 2015.

[34] A. C. Ferrari, J. C. Meyer, V. Scardaci et al., "Raman spectrum of graphene and graphene layers," Physical Review Letters, vol. 97 , no. $18,2006$.

[35] R. Schönfelder, M. H. Rümmeli, W. Gruner et al., "Purification-induced sidewall functionalization of magnetically pure single-walled carbon nanotubes," Nanotechnol, vol. 18, no. 37, 2007.

[36] F. Tuinstra and J. L. Koenig, "Raman spectrum of graphite," The Journal of Chemical Physics, vol. 53, no. 3, pp. 11261130, 1970.

[37] O. Polydorou, K. Pelz, and P. Hahn, “Antibacterial effect of an ozone device and its comparison with two dentin-bonding systems," European Journal of Oral Sciences, vol. 114, no. 4, pp. 349-353, 2006.

[38] L. M. Malard, M. A. Pimenta, G. Dresselhaus, and M. S. Dresselhaus, "Raman spectroscopy in graphene," Physics Reports, vol. 473, no. 5-6, pp. 51-87, 2009.

[39] J. Lai, B. Sunderland, J. Xue et al., "Study on hydrophilicity of polymer surfaces improved by plasma treatment," Applied Surface Science, vol. 252, no. 10, pp. 3375-3379, 2006.

[40] J. Hasan, R. J. Crawford, and E. P. Ivanova, "Antibacterial surfaces: the quest for a new generation of biomaterials," Trends in Biotechnology, vol. 31, no. 5, pp. 295-304, 2013.

[41] M. Kalbacova, A. Broz, J. Kong, and M. Kalbac, "Graphene substrates promote adherence of human osteoblasts and mesenchymal stromal cells," Carbon, vol. 48, no. 15, pp. 4323$4329,2010$.

[42] T. Kanno, T. Takahashi, T. Tsujisawa, W. Ariyoshi, and T. Nishihara, "Platelet-rich plasma enhances human osteoblast-like cell proliferation and differentiation," Journal of Oral and Maxillofacial Surgery, vol. 63, no. 3, pp. 362-369, 2005.

[43] T. Yuranova, A. G. Rincon, A. Bozzi et al., "Antibacterial textiles prepared by RF-plasma and vacuum-UV mediated deposition of silver," Journal of Photochemistry and Photobiology A: Chemistry, vol. 161, no. 1, pp. 27-34, 2003. 


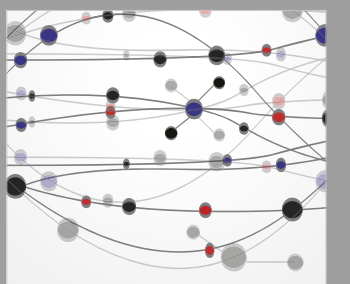

The Scientific World Journal
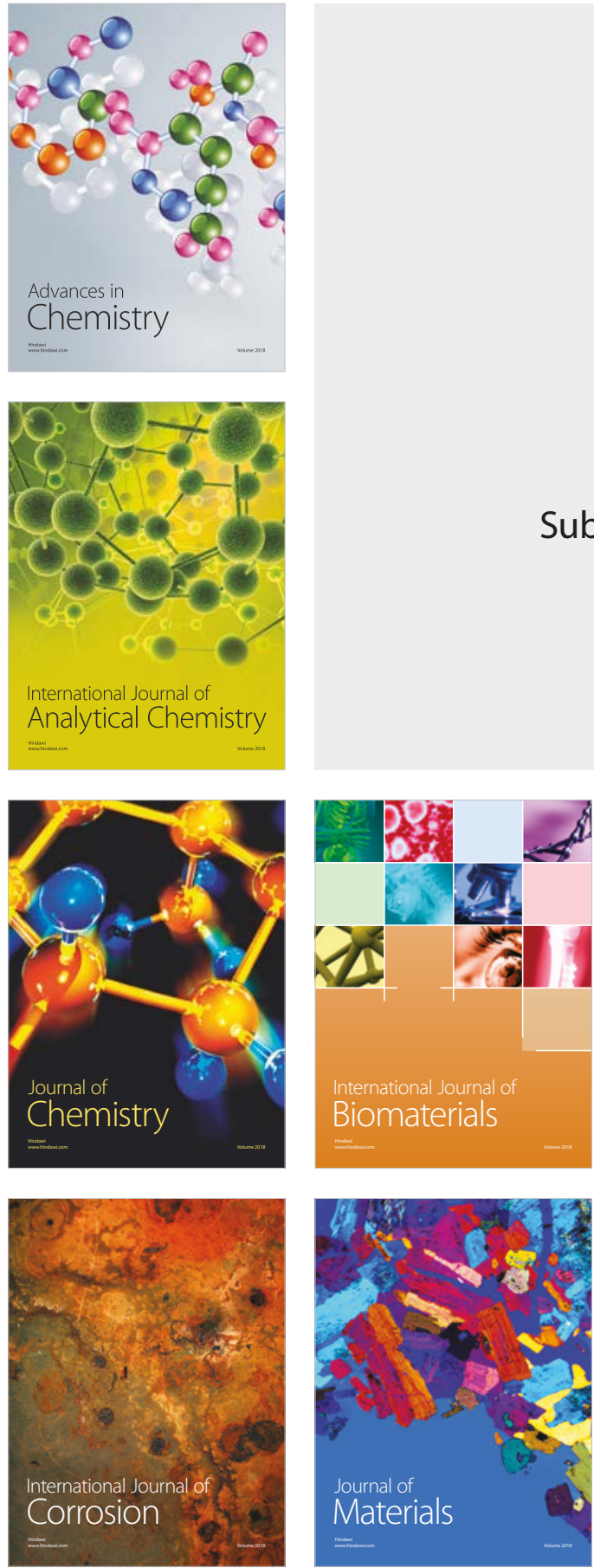

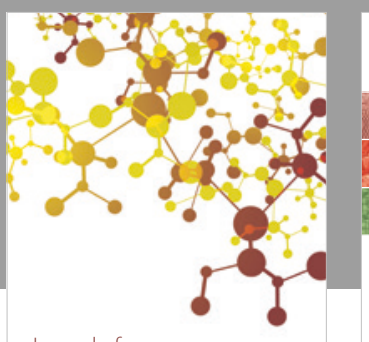

Journal of

Applied Chemistry
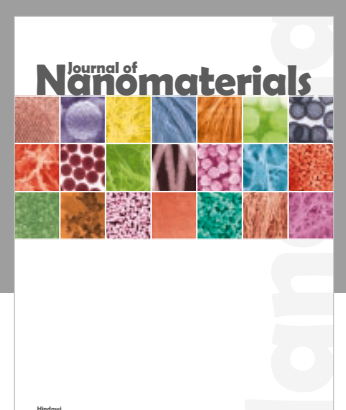

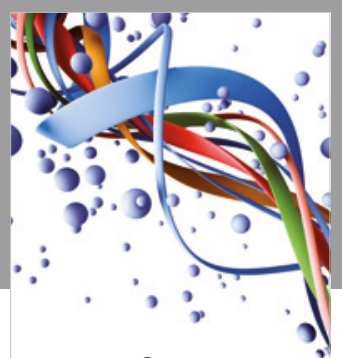

Scientifica

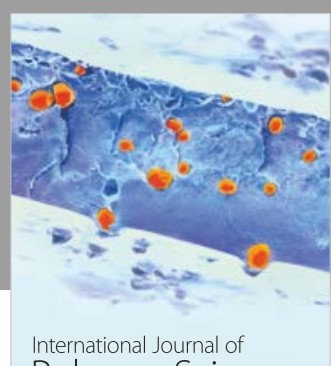

Polymer Science

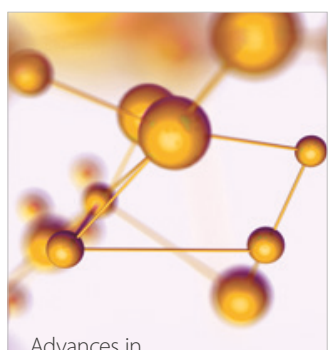

Physical Chemistry
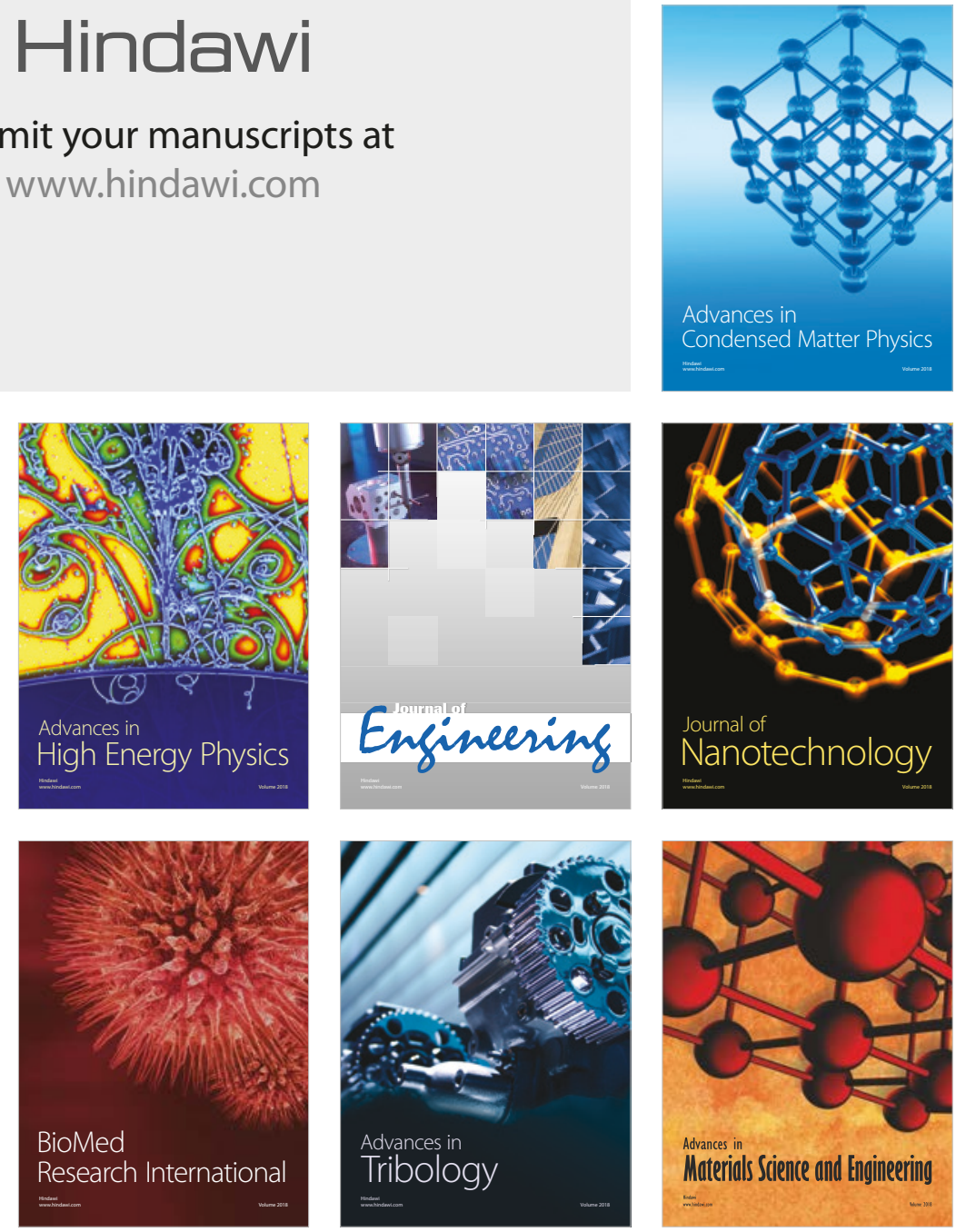